\title{
Wind potential evaluation in the Canary Islands using GIS
}

\author{
Julieta Schallenberg-Rodríguez ${ }^{1}$, Jesús Notario del Pino ${ }^{2}$ \\ ${ }^{1}$ Department of Process Engineering \\ University of Las Palmas de Gran Canaria \\ Campus de Tafira, 35016 Las Palmas de Gran Canaria (Spain) \\ Phone number: +34 928 451936, e-mail: jschallenberg@ dip.ulpgc.es \\ ${ }^{2}$ Department of Soil Science and Geology \\ University of La Laguna \\ Astrofisico Francisco Sanchez Av., 38204 La Laguna (Spain) \\ Phone number: +34 922 318426, e-mail: jnotario@ull.es
}

\begin{abstract}
The Canary Islands (Spain) are highly dependent on external energy sources. For 2015, the Canarian Energy Plan establishes that $30 \%$ of the electricity demand will be covered by renewable energy sources, mainly wind and solar (the goal for wind energy is $1025 \mathrm{MW}$ ). Therefore, it is crucial to determine the wind potential for each island as a first step for the energy planning. Within this work, a novel methodology based on GIS (Geographical Information System) for the determination of the wind potential is proposed. As a first step, the available land for wind exploitation per island is determined. For this purpose several territorial constrains are taken into account (natural reserves, inhabited areas, roads, etc.). Another type of constrain is the wind velocity (minimum wind speed for wind exploitation purposes). Once all these constraints have been applied, each island' s map shows the available land for wind production. At this stage wind farms are located in these areas. Finally the wind energy production per wind farm is calculated. For this, the annual energy yield is calculated as a function of the Weibull distribution.
\end{abstract}

Key words: Wind, potential, GIS, Canary Islands

\section{Motivation}

The Canary Islands are highly dependent on external energy sources, $98 \%$ of the primary energy consumption is based on imported oil. Speaking about electricity, this percentage decreases to $91 \%$. The Canary Islands had no conventional energy sources, but they have plenty of renewable resources, mainly wind and solar.

For the Canary Islands it is very important to increase the level of energy self-sufficiency. This can only be done through the deployment of renewable energy sources (RES). Renewable energies are autochthonous energy sources and they can contribute to reduce dependency from energy imports and to the diversification of energy sources. In the same way, the development of RES can actively contribute to the creation of employment and to encourage regional development. All these facts gain special importance in a region like the Canary Islands.

The electrical power installed in the Canary Islands at the end of 2009 was $2832 \mathrm{MW}$, the renewable energies came up to $9,8 \%$ of the total installed power but in terms of production this percentage was $8,7 \%$. The RES installed on the Canary Islands are mainly wind and solar photovoltaic, $142 \mathrm{MW}$ and ca. $100 \mathrm{MW}$ respectively.

For the year 2015, the Canarian Energy Plan establish that $30 \%$ of the electricity demand will be covered by RES, mainly wind and solar. This plan establishes, for instance, that wind energy will reach $1025 \mathrm{MW}$, photovoltaic 160 MW and waves $50 \mathrm{MW}$.

These figures for RES implementation already confront the electrical grid operator with stability issues, among others challenges. Several strategies are under study aiming at reducing the peak load and/or increasing the base load in order to allow the increase of intermittent RES penetration into the electrical grids. The strategies under consideration are, among others, hydro storage systems (wind-hydro pumping stations).

Taking into account this context, it is crucial to determine the wind potential in each island as a first step for the energy planning. For this purpose a methodology based on GIS (Geographical Information Systems) has been used to determine accurately this potential. The evaluation of the wind potential using GIS allows the quantification of the potential wind -energy production and, at the same time, it allows also to locate where this production will take place. This is vital to determine the cost of the resource, 
but also for the planning phase since other parameters could also be taken into account, e.g. if there are electrical grids available or there is a need for grid reinforcement or if water storage system are viable, etc.

\section{Methodology}

\section{Potential and limitations}

The theoretical potential comprises the entire physical energy supply available without considering any restrictions. It represents the theoretical maximum for the use of RES. In order to determine the technical potential, the theoretical potential is reduced by considering technical and geographical constraints. Important technical and geographical restrictions that have to be considered are the available conversion technologies, conversion losses, location availability (e.g. possible locations to install wind turbines) or other limitations. The technical potential is dynamic as technology develops over time and it represents the maximum potential that can be explored up to a certain point in time.

The available potential is defined here as the part of the theoretical potential that can be harvested easily and in a sustainable manner with the existing technology. The restrictions defining the available potential act as exclusion criteria, which eliminate areas with characteristics prohibiting the exploitation of wind energy. These restrictions are referred in this paper as constraints.

\section{Constraints}

Two main factors influence the available wind energy potential: the local wind regime and the available land for the installation of windturbines.

\section{Territorial constraints}

Territorial constraints are identified through a literature review and examination of government laws and regulations.

A first constraint in this study is the restriction to onshore areas only. The onshore area available for wind power is further restricted to areas that are suitable for wind turbine installation.

The territorial constraints as well as its buffer areas are summarized in table 1.

Table 1: Territorial constrains \& buffer areas

\begin{tabular}{ll}
\hline Restricted areas & Buffer area \\
\hline Protected areas: & \\
- National Parks & \\
- Natural Parks & \\
- Rural Parks & \\
- Integral Natural Reserves & \\
- Special Natural Reserves & $1000 \mathrm{~m}$ \\
- Natural Monuments & \\
- Protected landscapes & \\
- Sites of Special Scientific Interest & \\
- NATURA 2000: Special & \\
& \\
& Protection Areas (SPAs) for birds \\
& \& Special Areas of Conservation \\
& \\
(SACs) & \\
Isolated house & \\
Inhabited area & $150 \mathrm{~m}$ \\
\hline
\end{tabular}

\begin{tabular}{ll} 
Water reservoir & \\
Roads & $120 \mathrm{~m}$ \\
Aerial electrical grids & $120 \mathrm{~m}$ \\
& Trunk-conical area \\
& at the end of both \\
& sides of the \\
Airports & airstrip of $3500 \mathrm{~m}$ \\
& long and $10^{\circ}$ \\
& aperture angle \\
\hline
\end{tabular}

Figure 1: Protected areas on Tenerife island

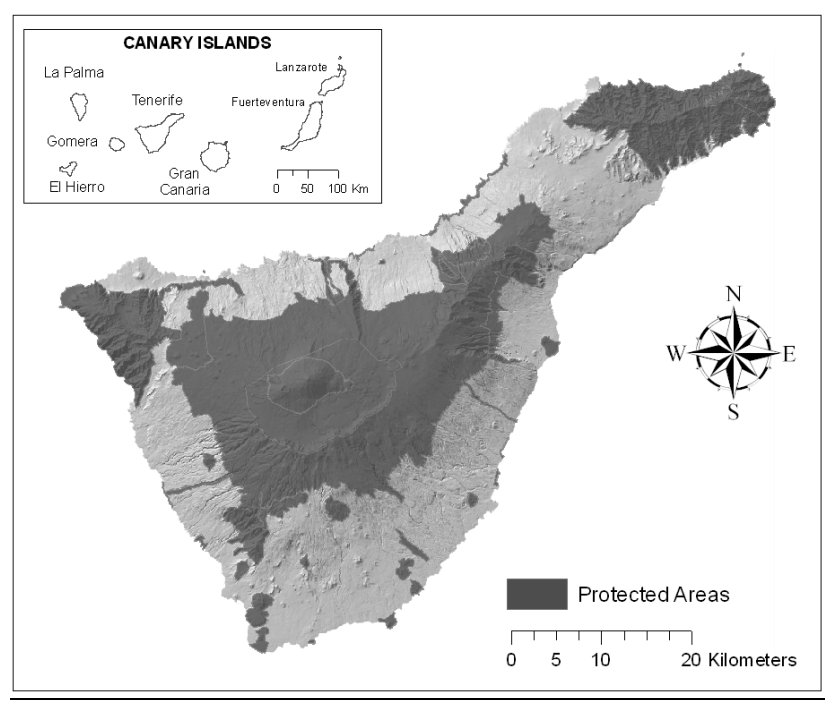

$\underline{\text { Wind constrains }}$

A second kind of restriction is determined by the local wind conditions. Locations with an average wind speed below $5 \mathrm{~m} / \mathrm{s}$ at the hub height will not be taken into consideration for this research, since the economical feasibility is considered to be too low.

\section{Land available for wind production and wind farm location}

Once both constraints have been implemented at the map level, the areas where the wind farms can be located are shown. At this stage a further territorial constraint has been implemented since the maps show some areas of very small dimensions available for wind installations. This constraint consists on the elimination of these small areas and the restriction is applied to available areas with a smaller diameter than 50 meters.

Once all the mentioned constrains have been applied, each island's map shows the available land for wind production. At this stage wind farms are located in these available areas. The wind farms take a matrix shape where the array efficiency $\left(\eta_{a r}\right)$ is proportional to the interturbine and inter-row spacing as a function of the rotor diameter. The array efficiency is the efficiency of a whole wind farm, which decreases with closer spacing due to the interference of wind turbines.

\section{Wind energy production}

There are several methods to try to estimate the wind energy production. One of the possibilities is to establish 
the windturbine to be installed as a starting point. Then the characteristic curve of this particular windturbine is used to determine the energy production as a function of the wind distribution on-site.

This has been the method used in this case. The reference windturbine (WT) selected for this purpose is a $2 \mathrm{MW}$ one with a hub height of 80 meters. This WT size, with this hub high, is currently broadly installed. In the Canary Islands no one of this size has already been installed. However, a good part of the projects submitted in the last wind call for tender published in the Canary Islands where projects with WTs around $2 \mathrm{MW}$; therefore this seems to be also the tendency in the islands.

In order to improve the results, a sensibility analysis has been carried out in order to test the variability of the results as a function of the WT's selection. The sensibility analysis was carried out taking into consideration two different approaches:

a) Hub high sensibility: the same WT of $2 \mathrm{MW}$ was tested at $60 \mathrm{~m}, 80 \mathrm{~m}$ and $100 \mathrm{~m}$ hub high.

b) Size sensibility: 3 different WT's sizes were tested: 1, 2 and $5 \mathrm{MW}$. The hub high was $80 \mathrm{~m}$ for all the three WTs.

Wind data needed: wind speed and $k$ shape factor of the Weibull distribution on-site, are available in the wind database used. This database uses grid cells of 100 x 100 meters (the data can be consulted at: http://www.itccanarias.org/recursoeolico/island_cells/inde x.html).

Table 2 shows a sample of the wind data used within this research. In this table 23 grids corresponding to the island of Gran Canaria are shown. The first 2 columns indicates the geo-localisation coordinates; the next columns indicates the wind speed $(\mathrm{m} / \mathrm{s})$ and the value of the $k$ shape factor of the Weibull distribution at 60 and 80 meters high; and, finally, the last column indicates the predominant wind direction. The database used includes also the wind speed and $k$ shape factor at $40 \mathrm{~m}$ high. In order to calculate wind speeds and $k$ shape factors a method of interpolation has been used.

Table 2: $\quad$ Sample of wind data (Gran Canaria)

\begin{tabular}{|c|c|c|c|c|c|c|}
\hline $\mathrm{X}$ & Y & $\begin{array}{c}\text { Wind } \\
\text { speed } \\
60\end{array}$ & $\begin{array}{c}\mathrm{k} \\
\text { Weib } \\
60\end{array}$ & $\begin{array}{c}\text { Wind } \\
\text { speed } \\
80\end{array}$ & $\begin{array}{c}\mathrm{k} \\
\text { Weib } \\
80\end{array}$ & $\begin{array}{c}\text { Direc- } \\
\text { tion }\end{array}$ \\
\hline 402850 & 3106650 & 9,29 & 2,156 & 9,49 & 2,178 & NNE \\
\hline 402850 & 3106550 & 9,29 & 2,155 & 9,5 & 2,177 & NNE \\
\hline 402850 & 3106450 & 9,3 & 2,155 & 9,51 & 2,177 & NNE \\
\hline 402950 & 3106950 & 9,27 & 2,16 & 9,47 & 2,18 & NNE \\
\hline 402950 & 3106850 & 9,27 & 2,159 & 9,48 & 2,179 & NNE \\
\hline 402950 & 3106750 & 9,28 & 2,158 & 9,49 & 2,178 & NNE \\
\hline 402950 & 3106650 & 9,29 & 2,157 & 9,49 & 2,178 & NNE \\
\hline 402950 & 3106550 & 9,29 & 2,156 & 9,5 & 2,177 & NNE \\
\hline 402950 & 3106450 & 9,3 & 2,155 & 9,51 & 2,177 & NNE \\
\hline 403050 & 3107150 & 9,25 & 2,162 & 9,46 & 2,181 & NNE \\
\hline 403050 & 3107050 & 9,26 & 2,161 & 9,46 & 2,18 & NNE \\
\hline 403050 & 3106950 & 9,26 & 2,16 & 9,47 & 2,18 & NNE \\
\hline 403050 & 3106850 & 9,27 & 2,159 & 9,48 & 2,179 & NNE \\
\hline 403050 & 3106750 & 9,28 & 2,158 & 9,49 & 2,179 & NNE \\
\hline 403050 & 3106650 & 9,29 & 2,158 & 9,49 & 2,178 & NNE \\
\hline 403050 & 3106550 & 9,3 & 2,157 & 9,5 & 2,177 & NNE \\
\hline
\end{tabular}

\begin{tabular}{ccccccc}
\hline 403050 & 3106450 & 9,3 & 2,156 & 9,51 & 2,177 & NNE \\
403150 & 3107350 & 9,23 & 2,165 & 9,44 & 2,183 & NNE \\
403150 & 3107250 & 9,24 & 2,164 & 9,45 & 2,182 & NNE \\
403150 & 3107150 & 9,25 & 2,163 & 9,46 & 2,181 & NNE \\
403150 & 3107050 & 9,26 & 2,162 & 9,46 & 2,18 & NNE \\
403150 & 3106950 & 9,26 & 2,161 & 9,47 & 2,18 & NNE \\
403150 & 3106850 & 9,27 & 2,16 & 9,48 & 2,179 & NNE \\
\hline
\end{tabular}

Source: www.itccanarias.org/recursoeolico

In the Weibull distribution, the variations in wind velocity are characterized by two functions:

(1) the probability density function and

(2) the cumulative distribution function.

The annual energy yield can be obtained as:

$$
E=\frac{8760}{100} \sum_{v E}^{v A} \mathrm{Pel} \cdot \emptyset
$$

where the power output $\mathrm{P}_{\mathrm{el}}$ is given in $\mathrm{kW}$ and the wind frequency distribution $\Phi$ in $\%$.

The annual energy yield is then obtained by summing from $v_{E}$ (cut-in wind speed) to $v_{A}$ (cut-out wind speed), the duration of the wind velocity within an interval being given in hours in accordance with the frequency distribution. The annual energy yield is the integral of power over time.

\section{Results}

The methodology proposed ends up with the determination of the annual wind energy production per island and the wind farms located on each island's map. The wind energy production per island is then compared to the electricity demand per island, in order to estimate the percentage of electricity demand that can be covered by wind energy.

\section{References}

[1] Archer, C. L., Jacobson, M. Z. 2005. Evaluation of global wind power. Journal of Geophysics Resources 110.

[2] Aydin N.Y. et al. 2010. GIS-based environmental assessment of wind energy systems for spatial planning: A case study from Western Turkey. Renewable and Sustainable Energy Reviews 14. 364-373

[3] Baban S.M.J, Parry, T. 2001. Developing and applying a GIS-assisted approach to locating wind farms in the UK. Renewable Energy; 24:59-71.

[4] Consejería de Industria, Comercio y Nuevas Tecnologías (Regional Ministry of Industry, Trade and New Technologies). 2006. Decreto 32/2006, de 27 de marzo, por el que se regula la instalación y explotación de los parques eólicos en el ámbito de la Comunidad Autónoma de Canarias.

[5] European Environment Agency. 2009. Europe's onshore and offshore wind energy potential: an assessment of environmental and economic constraints. EEA-Technical report.

[6] Grubb, M.J., Meyer, N.I., 1993. Wind energy: resources, systems, and regional strategies. In: Johansson, T.B., Kelly, H., Reddy, A.K.N., Williams, R.H. (Eds.), Renewable Energy: Sources for Fuels and Electricity. Island Press, Washington, DC, pp. 157-212.

[7] Hasen, H. S. 2005. GIS-based Multi-Criteria Analysis of Wind Farm Development. Proceedings of the $10^{\text {th }}$ Scandinavian Research Conference on Geographical 
Information Science (ScanGIS), Stockholm, Sweden, 13 - 15 June.

[8] Hau, E. 2006. Wind Turbines: Fundamentals, Technologies, Application, Economics. $2^{\text {nd }}$ Edition. Springer.

[9] Held, A. et al. 2008. Deriving Cost-Resources Curves for Wind-Onshore Energy in the EU using a Geographical Information System. Proceedings of the $31^{\text {st }}$ IAEE International Conference, Istanbul.

[10] Hoogwijk, M. et al. 2004. Assessment of the global and regional geographical, technical and economic potential of onshore wind energy. Energy Economics 26; 889-919

[11] Krewitt, W., Nitsch, J. 2003. The potential for electricity generation from on-shore wind energy under the constraints of nature conservation: a case study for two regions in Germany. Renewable Energy 28.1645-1655

[12] Mathew, S. 2006. Wind Energy. Fundamentals, Resource Analysis and Economics.

[13] Ramirez-Rosado I. J. et al. 2008. Promotion of new wind farms based on a decision support system. Renewable Energy. 33:558-66.

[14] Stiebler, M. 2008. Wind Energy Systems for Electric Power Generation. Springer

[15] Voivontas, D. et al. 1998. Evaluation of renewable energy potential using a GIS decision support system. Renewable Energy, Vol. 13, No. 3, pp. 333344.

[16] Yue, C. D., Wang, S. S. 2006. GIS-based evaluation of multifarious local renewable energy sources: a case study of the Chingu area of southwestern Taiwan. Energy Policy. 34:730-42. 